\title{
Health-related quality of life in patients with pediatric onset of end-stage renal disease: state of the art and recommendations for clinical practice
}

\author{
Lidwien A. Tjaden ${ }^{1,2}$ - Martha A. Grootenhuis ${ }^{3}$ - Marlies Noordzij ${ }^{2}$. \\ Jaap W. Groothoff ${ }^{1}$
}

Received: 18 March 2015 /Revised: 21 July 2015 / Accepted: 27 July 2015 / Published online: 27 August 2015

(C) The Author(s) 2015. This article is published with open access at Springerlink.com

\begin{abstract}
Health-related quality of life (HRQoL) is increasingly recognized as a key outcome in both clinical and research settings in the pediatric population with end-stage renal disease (ESRD). This review aims to: (1) summarize the current knowledge on HRQoL and socioprofessional outcomes and (2) provide strategies for incorporation of HRQoL assessment into clinical practice. Studies report that pediatric patients with ESRD have significantly lower HRQoL scores compared with children with other chronic diseases. Patients treated by dialysis are at particularly high risk for impaired HRQoL. Furthermore, patients more often have impaired neurocognitive functioning and lower academic achievement. Important determinants of impaired HRQoL include medical factors (i.e., receiving dialysis, disabling comorbidities, cosmetic side effects, stunted growth), sociodemographic factors (i.e., female gender, non-Western background) and psychosocial factors (i.e., noneffective coping strategies). Contrary to the situation in childhood, adult survivors of pediatric ESRD report a normal mental HRQoL. Despite this subjective feeling of well-being, these patients have on average experienced significantly more difficulties in completing their education, developing intimate relationships, and securing employment. Several medical and psychosocial strategies may potentially improve HRQoL in children with ESRD. Regular assessment
\end{abstract}

Jaap W. Groothoff

j.w.groothoff@amc.uva.nl

1 Department of Pediatric Nephrology, Emma Children's Hospital, Academic Medical Center, Amsterdam, The Netherlands

2 Department of Medical Informatics, Academic Medical Center, Amsterdam, The Netherlands

3 Psychosocial Department, Emma Children's Hospital, Academic Medical Center, Amsterdam, The Netherlands of HRQoL and neurocognitive functioning in order to identify areas in which therapies and interventions may be required should be part of standard clinical care.

Keywords End-stage renal disease $\cdot$ Health-related quality of life $\cdot$ Neurocognitive functioning $\cdot$ Social outcomes $\cdot$ Renal replacement therapy

\section{Introduction}

Medical and surgical advances have led to dramatic changes in physical outcomes and substantial improvement in survival rates for children with end-stage renal disease (ESRD) [1,2]. Consequently, more children with ESRD are living with the burden of long-term renal replacement therapy (RRT), a timeconsuming and invasive treatment that places high demands on children and their families. Outcomes typically measured in clinical trials include survival rates and biochemical and physiological values. However, a focus on health-related quality of life (HRQoL) is needed to address the psychosocial well-being of these children and to understand the impact of the disease and its treatment on their lives.

HRQoL is therefore increasingly recognized as a key outcome in both clinical and research settings in the pediatric ESRD population [3-5].

Accurate measurement of HRQoL in children, however, has proven to be complex, and different tools have been used to this end. The purpose of our review is to give an overview of knowledge on HRQoL, neurocognitive functioning, and other social outcomes in pediatric ESRD patients (as assessed by themselves and by their caregivers) and to provide strategies for incorporation of HRQoL assessment into clinical practice. 


\section{Quality of life: concepts and measurement instruments}

Based on the World Health Organization's definition, QoL has been conceptualized as a multidimensional and subjective construct that reflects an individual's subjective assessment of several domains of his or her life, including physical, social, and psychological functioning [6]. It is a broad-ranging concept affected in a complex way by the person's physical health, psychological state, level of independence, social relationships, and personal expectations. The restriction to HRQoL refers to the inclusion of dimensions that are relevant to health and are affected by ill health, such as dimensions of mobility, pain, and psychosocial well-being [7].

Several different approaches have been reported to assess HRQoL in the pediatric ESRD population, including health status measurements that evaluate one or more health domains [8-16] and qualitative methods [17, 18] (Table 1). Health status measurements can be structured as either generic or disease specific. Generic measures such as the Pediatric Quality of Life Inventory, version 4.0 ( PedsQL 4.0), the TACQOL [TNO-AZL (Netherlands Organisation for Applied Scientific Research Academic Medical Centre) Children's Quality Of Life Questionnaire], and the Child Health and Illness Profile-Adolescent Edition (CHIP-AE), are designed to assess and compare the health status of patients with different diseases and may provide valuable information for comparing outcomes between sick and healthy populations. They are generally well validated and reliable but are often not recommended for work involving evaluation of randomized controlled trials, as they lack sensitivity to detect small but clinically significant changes over time or due to treatment for specific diseases. Disease-specific measurements, like the PedsQL ESRD 3.0, are more suitable to assess the impact of a particular disease or treatment. These measures include items that are likely to be affected by the specific disease and are therefore more responsive to clinically significant changes [5].

To assess the quality of HRQoL questionnaires, psychometric properties including reliability and validity are used. Reliability refers to the degree to which an assessment tool produces stable and consistent results and is measured by Cronbach's $\alpha$. Measures with a Cronbach's $\alpha \geq 0.7$ are considered sufficiently reliable [23]. Even though none of the questionnaires used in the pediatric ESRD population have specifically been validated in this population, all questionnaires do fulfil these criteria based on studies conducted in children with other chronic diseases [19-22, 24, 25] (Table 1). Finally, more qualitative methods (i.e., in-depth interviews and focus groups) have been used to elicit in-depth and detailed insights about the impact of the disease and treatment from the patient's perspective, much of which remain unspoken during clinical encounters. These methods might expose issues that are not included in questionnaires and therefore provide a broader scope patient needs and feeling of well-being.

Measuring HRQoL in children is challenging. The relevant domains of pediatric HRQoL questionnaires differ from those in the adult population and need to be adjusted to the child's specific developmental age. Furthermore, a common methodological criticism on published pediatric HRQoL studies is the use of a single informant, i.e., either caregiver or child. Observations of caregiver-child disagreement about HRQoL, particularly prominent in adolescent populations, have led to endorsement of multi-informant ratings of HRQoL [26-28]. Other limitations with regard to HRQoL research are related to the small sample sizes used in most studies. It is therefore difficult to generalize findings to a larger population and to undertake valid subgroup comparisons (i.e., based on medical history, social economic status, etc.). Finally, most studies use a cross-sectional design in which changes over time are not assessed. Therefore, definite information about the effect of time cannot be provided.

\section{HRQoL in children with ESRD}

A growing number of studies have assessed the impact of RRT on the lives of children with ESRD $[9,10,12,13,15,17,18$, 29-34]. These children have to face several challenges, including frequent hospitalization, painful medical procedures, school absence, and restriction of activities. As a result, they are vulnerable to a multitude of short- and long-term academic, behavioral, and negative emotional outcomes, such as withdrawn behavior. According to several studies conducted in both Europe and the USA, pediatric ESRD patients have significantly lower HRQoL scores compared with healthy children of the same age, especially concerning physical functioning in those treated by dialysis [11-13, 29, 32, 35]. Furthermore, a study from the USA of 2500 pediatric patients from ten different physician-diagnosed disease clusters [36] found that patients with ESRD had significantly worse HRQoL scores compared to children with other chronic illnesses (including diabetes, cardiac conditions, asthma, and severe obesity) on the PedsQL 4.0 domains of physical health, psychological health, social functioning, and school functioning.

\section{Important determinants of HRQoL and proposed interventions}

\section{Medical factors}

As expected, the most important medical determinants associated with impaired HRQoL in the pediatric ESRD population are being on dialysis and the existence of comorbidities, such as cardiovascular diseases, underlying syndromes, 


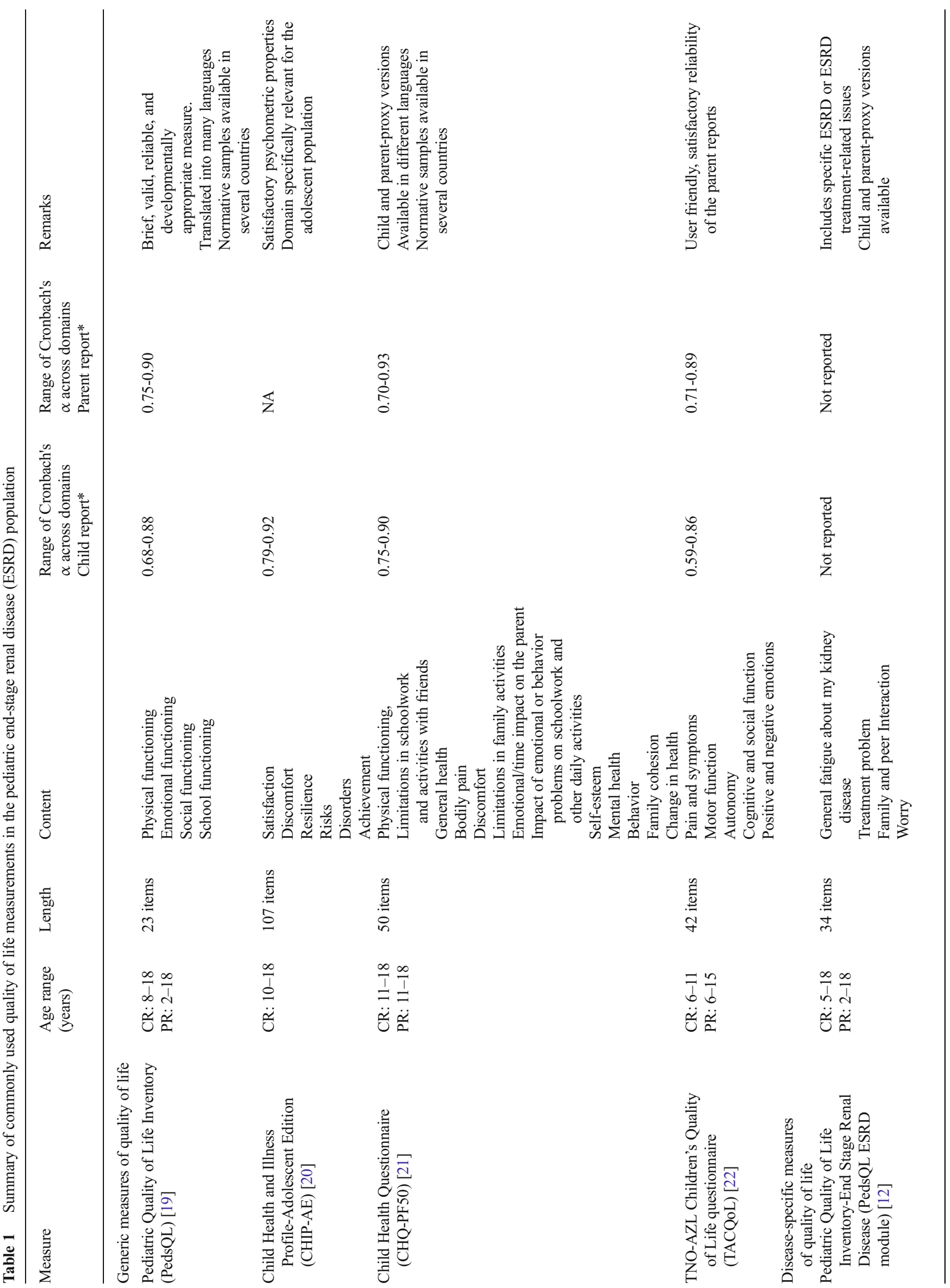


urological malformations, endocrinologic disorders, and gastrointestinal diseases $[8,10,11,29,37]$. Due to small number of patients, most studies could not draw any conclusion about the impact of individual comorbidities. However, in particular, comorbidities that tend to represent an obstacle to social activities, such as urological malformations leading to urinary incontinence and the necessity of undergoing catheterization, may be prone to negatively affect HRQoL $[37,38]$.

Studies report statistically significantly higher HRQoL scores in children with a functioning renal graft, including improved physical activity, greater satisfaction, less discomfort, and better school functioning [8, 13-16, 29, 34, 39, 40]. Some studies even report similar HRQoL scores in pediatric patients with a renal transplant compared with the general population $[11,16]$. However, contrary to these high generic scores, data from the disease-specific PedsQL 3.0 ESRD module reveal significant specific problems among transplanted children of all ages. These children reported a high level of concern regarding physical appearance as well as problems attributed to kidney issues (e.g., swelling, thirst, headache), and they have more frequent school disruption and difficulties with family and peer interaction [10, 13,31]. Not surprisingly, patients who experienced a rejection episode reported the most physical discomfort [11]. The consequences of cosmetic side effects of immunosuppressive therapy, such as weight gain, gingival hypertrophy, acne, and cushingoid appearance are important but underestimated problems in patients with a functioning renal graft, particularly in the adolescent population [29, 33, 41-44] (Table 2). Proposed strategies to minimize the consequences of medication side effects and thereby improve HRQoL include managing changes in appearance by learning cosmetic application techniques and combating weight gain through physical exercise [45].

In children undergoing dialysis, pronounced impairments have been reported in the domains of physical health. Surprisingly, most studies did not find significant differences in HRQoL scores between patients on hemodialysis (HD) and those on peritoneal dialysis (PD) $[8,9,17]$. It has been suggested that this lack of difference could partly be linked to the labor-intensive effort for the family associated with PD treatment, which could somewhat invalidate the advantages of more freedom and less disruption of daily life [46]. Contrary to the equality of the (low) HRQoL scores in both dialysis modalities, some studies have identified other advantages of PD over HD, such as fewer dietary restrictionsand less disruption to home- and school-based activities [47, 48]. In addition, authors of a qualitative study using in-depth interviews found that pediatric patients perceived home HD to offer greater flexibility and freedom to live a more normal life [18] compared with patients receiving long-term hospital dialysis, who indicated they felt imprisoned and were frustrated about the restrictive and unrelenting dialysis schedule. In a study conducted in the USA, home nocturnal HD was found feasible for 


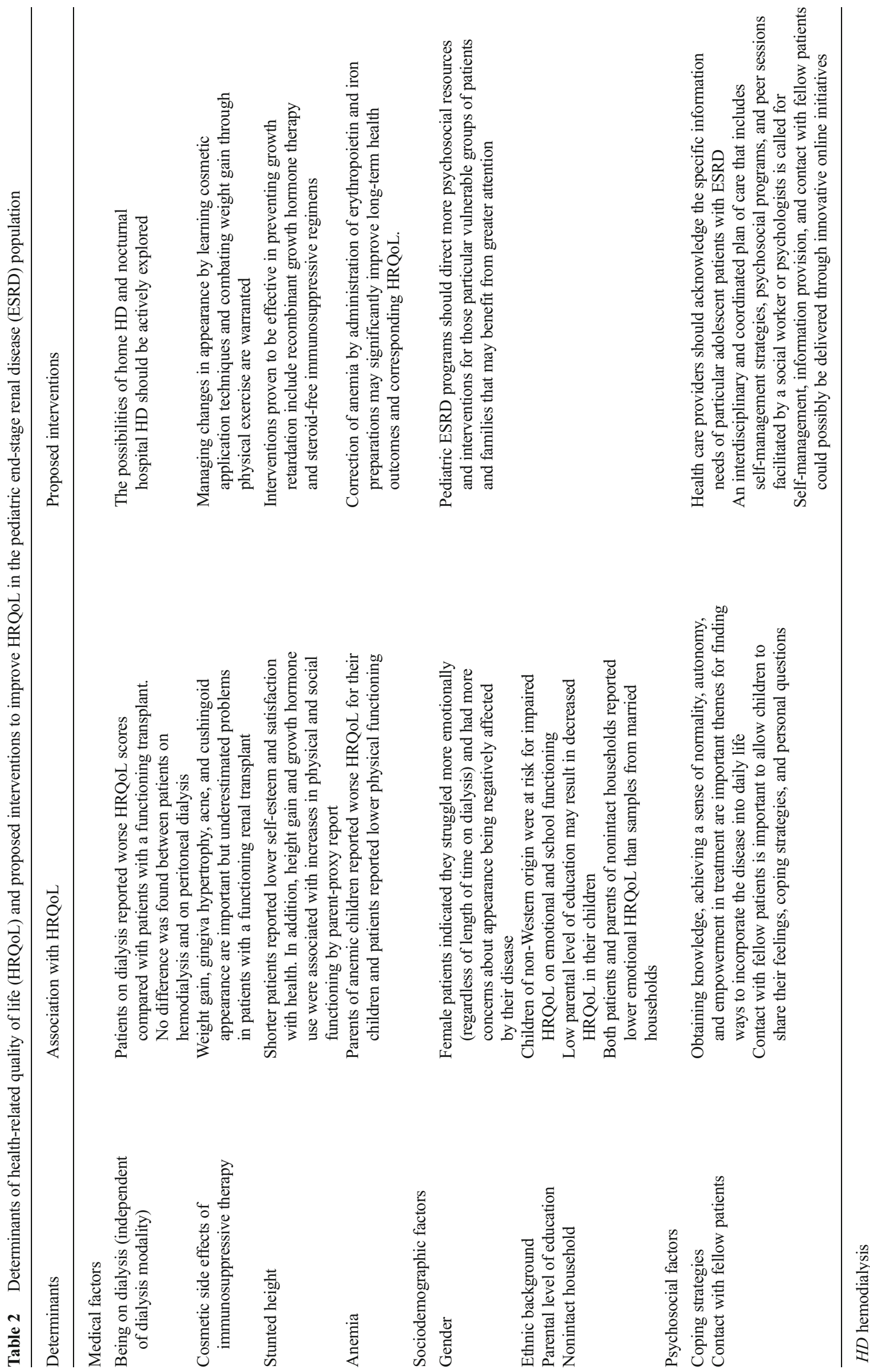


selected adolescents, and it improved their QoL and school attendance but increased family burden [49]. Currently, pediatric home HD programs are not readily available. This is partly due to resource and logistic constraints but also because they require a substantial commitment by the training center, patient, and his or her family [50,51]. A recent study suggests that hospital-based nocturnal HD might be another alternative, as it can offer better uremia-associated outcomes, reduces dietary and fluid restrictions, and improved QoL and school attendance [52].

Other medical factors associated with HRQoL scores include (final) height and hemoglobin level. In a Spanish study of 81 pediatric ESRD patients, the authors found that shorter patients reported lower self-esteem and lower satisfaction with health [11]. In addition, a 2-year follow-up study [53] measured the impact of short stature on HRQoL in 483 children with chronic kidney disease (CKD) and revealed that height gains and growth hormone use were associated with increases in physical and social functioning, according to parent-proxy report. Since recent data show that $43 \%$ of patients with childhood-onset ESRD do not achieve an adult height within the normal range [54], there is certainly room for improvement with respect to reducing the extent of stunted growth. Treatment strategies shown to be effective in preventing growth retardation in patients with ESRD consist of correcting any nutritional, water, and salt deficiencies and metabolic abnormalities, especially in young infants [55]. Also, recombinant growth hormone (rhGH) therapy is safe and efficacious in children [56]. However, a recent European study showed that in several European countries, only a minority of children on dialysis with short stature actually received rhGH, in contrast to local policies [54]. Pediatric nephrologists should therefore more vigorously implement these growth-stimulating therapies in their management of children with ESRD.

Physicians should also pay sufficient attention to the correction of anemia. Parents of anemic children with CKD reported worse HRQoL scores [57], and other studies found lower physical functioning in anemic patients receiving dialysis [58] or with a functioning transplant [11]. Correcting anemia by administering erythropoietin and iron preparations may significantly improve long-term health outcomes for children with kidney disease, resulting in improved HRQoL [59, 60].

\section{Sociodemographic factors}

Female gender is associated with impaired HRQoL in the pediatric ESRD population [9] (Table 2). Girls indicated more often that they struggled emotionally and had concerns about their appearance being negatively affected by their disease, compared with their male counterparts. Surprisingly, neither age at the time of investigation or at the start of RRT could be associated in any way with HRQoL scores in pediatric patients with ESRD [10, 32, 36].

A study conducted in children with ESRD in The Netherlands, Belgium, and part of Germany [35] found that children of non-Western origin were at risk for impaired HRQoL on emotional- and school-functioning domains. Also, low parental level of education may result in a decreased HRQoL in their children's childhood [61], and both patients and parents being part of nonintact households reported lower emotional HRQoL than those from married households [8]. Pediatric ESRD programs should therefore direct more attention in terms of psychosocial resources and interventions to particularly vulnerable families (Table 2).

\section{Psychosocial factors}

Children with chronic illnesses use different coping strategies to deal with stressors in relation to their disease [62]. It has been suggested that by finding a way to incorporate the disease into their daily lives, these children might be able to adjust to some extent to their life-long chronic disease status. In the pediatric ESRD population, a few important themes have been identified, such as obtaining knowledge, achieving a sense of normality, and gaining autonomy and empowerment in the treatment [33]. Several studies conducted in the adolescent renal transplant population indicate that patients desire comprehensive information on technical, medical, and experimental aspects of surgery and posttransplant follow-up as well as on the effect on their physical appearance and of alcohol, drugs, and substance use on their disease [33, 34, 63, 64]. In addition, a study examining experiences and perspectives of adolescents waiting for a kidney transplant [18] identified strong apprehension about accepting a kidney from a living-related donor. The benefits of kidney transplantations were recognized, but the participants' optimism was partly quelled by concerns about the risks to their live donor in combination with the uncertainty about transplant survival. Health care providers should acknowledge these specific informational needs, and counselling should be integrated into clinical care to address and allay fears about kidney transplantation.

The overall lower HRQoL values among children receiving dialysis may reflect their sense of lack of control, social isolation, poor self-esteem, perceived inability to gain independence, uncertainties about their health and future, and lifestyle restrictions attributable to the time-consuming and onerous dialysis regimen [65]. An integrated clinic with ancillary services that address sufficient school and psychosocial support are therefore recommended and might even result in better clinical outcomes [66]. This also has important implications for transitional care, as the adult model of care may not address cognitive, emotional, and social needs of young people, and transition is often poorly coordinated. Furthermore, to enhance empowerment and autonomy, we suggest shared 
decision-making processes in which patients are actively involved in their own treatment decisions [67].

Studies also reveal the importance of social support in terms of contact with fellow patients, as this would encourage children to share their feelings, coping strategies, and personal questions $[17,18]$. Based on these findings, a communitybased young adult transplant service has been established in Oxford, UK. This clinic involves a peer session facilitated by a social worker and informal social activities, while the hospital team provides an outreach medical service. Surveys conducted among participants showed that this provided a better environment for peer interaction and support, which resulted in a higher clinical attendance rate, greater patient satisfaction and engagement, and reduced episodes of late rejection [68]. Furthermore, studies in adolescents with other chronic diseases demonstrated the potential value of Internet-based programs and mobile phone communication [69-71]. These results indicate that contact with fellow patients, but also a greater sense of self-management and access to information, could possibly be delivered through innovative online initiatives.

Moreover, given current economic constraints and scarcity of psychosocial services, it is particularly important to allocate resources in a cost-effective manner. Consistent and rigorous monitoring of HRQoL in children with ESRD might reveal specific problems at an early phase, thereby preventing further deterioration. In recent decades, there has been a growing interest in patient-reported outcomes (PROs) as a tool for pediatricians to use to discuss psychosocial issues during medical consultation [72]. When pediatric psychologists and pediatricians work together, PROs can be used to closely monitor children with chronic illnesses in a multidisciplinary context, and referral to psychosocial interventions can be better facilitated [73].

\section{Neurocognitive status, educational attainment, and social activities}

Neurocognitive dysfunction is a well-recognized complication of pediatric ESRD. Many studies found evidence of several neuropsychological deficits, including low scores for intelligence quotient (IQ), academic achievement, memory, and executive functioning [74-76]. In a large North American Study [Cronic Kidney Disease in Children (CKiD) of 386 children with CKD 2-4 (mean GFR 41), the overall neurocognitive functioning was comparable with the general population, but $21-40 \%$ of participants scored at least one standard deviation (SD) below the mean for IQ, academic achievement, attention regulation, or executive functioning [77]. The risk of developmental delay may be greatest for infants and young children on dialysis therapy because infancy is a period of rapid neurodevelopment, and approximately one half of brain growth takes place during the first years of life [78-81]. Therefore, early intervention programs designed to improve specific developmental areas, such as language abilities and motor function, should be sought. The neurodevelopmental status of older children and adolescents on dialysis therapy has been characterized by abnormal performance on tasks of verbal abstract ability, visual perceptual reasoning, memory, and visual motor skills compared with healthy children and transplant recipients [82]. It is therefore recommended that patients on dialysis therapy have age-appropriate cognitive and achievement testing conducted on a regular basis, especially if problems with school achievement exist.

Not surprisingly, ESRD and its treatment often decrease participation in peer and school-based activities. In a Turkish cohort of 211 children with ESRD, $50 \%$ of patients treated with dialysis and $37.9 \%$ of transplanted patients had left school without grading because of their illness [14]. This is in line with reports from the USA, where only $53 \%$ of patients receiving HD were able to successfully achieve full-time school attendance [83]. School attendance rates were higher among transplanted patients; however, even in this group, the impact of ESRD on academic functioning remained of particular concern for both patients and parents [9]. In addition, prolonged absence from school due to treatment-related issues can lead to a detrimental effect on sustaining peer relationships, self-esteem, and academic achievement, which negatively influences QoL [12, 15, 40, 84]. Therefore, regular school attendance should be a primary outcome measure of the overall success of RRT in children. Especially among school-aged children treated by dialysis, there is a need for strategies to optimize education opportunities. Dialysis units could have on-site educators to complement school-based teaching. There could be a close liaison with schools to offer appropriate support in reducing school absenteeism to a minimum. As noted earlier, attention could also be paid to identifying neurocognitive or behavioral abnormalities that may have a significant negative impact on the likelihood of success in the classroom. A psychologist-directed assessment can be particularly helpful as a means of detecting specific learning difficulties and targeting particular educational strategies [85].

\section{Child versus parent-proxy scores}

While the child's self-report should be considered the standard for measuring perceived HRQoL, there are circumstances, such as young age of the patient ( $<5$ years old) and cognitive impairment, in which a child is unable to complete a HRQoL instrument. In those cases, parent-proxy reports are mandatory. Scores from parents are not only relevant as a substitute for the child's HRQoL perception, but they also provide a more complete and comprehensive picture of the impact of the 
disease on the family. Second, they are important because it is typically the parents' perception of their child's well-being that influences health care use [86]. Therefore, using instruments that measure both parent and child perspectives is recommended. However, studies reveal a statistically and clinically significant discordance between parent and child HRQoL scores, with patients reporting higher scores than their caregivers [10, 87, 88]. Disagreement between parents' and children's reports of HRQoL is, in itself, unlikely to indicate that one of them is wrong or right, but rather is a consequence of different beliefs about the child's health and wellbeing. Due to their own grief about unfulfilled expectations for their child and concerns regarding the (long-term) impact of ESRD, parents may have a more negative view than their children [89]. A recent meta-analysis regarding discrepancies between child and parent-proxy HRQoL scores suggested that the differences in scores also depends on the HRQoL domain studied [86]. Parents tended to be more in agreement with their children on objective physical domains but less so in terms of emotional and social functioning and symptoms such as pain, fatigue, and gastrointestinal complaints. Limited knowledge due to respect for the child's privacy and autonomy may also be a factor accounting for the observed differences. In line with this hypothesis, a study in the UK among 428 pediatric patients with CKD and their parents [53] showed that concordance between child and parent perceptions of HRQoL was age dependent, with a lower correlation between self- and parent-proxy scores among adolescent patients compared with younger patients with ESRD. Obviously, the parents' own well-being may affect their perception of their child's HRQoL and symptoms. A poorer QoL, difficulties in managing the child's care, and higher levels of anxiety and maladaptive behavior have been identified in parents of children with ESRD [44, 90], which could result in a more negative view regarding their child's well-being. Therefore, sufficient support for families should also be incorporated into standard clinical care. This may prevent parent overprotectiveness and may, as such, indirectly lead to better medical outcomes and HRQoL in the child [91].

\section{Children reaching adulthood}

Few studies have reported on the effect of RRT in childhood on HRQoL and social functioning in adulthood. According to two studies [92, 93], adult patients with a functioning kidney transplant achieve normal scores on self-assessment of psychosocial and physical health. In a Dutch cohort study on the long-term effects of renal insufficiency in children (LERIC) we found that after 20-40 years of RRT [92], the proportion of impaired HRQoL in transplanted patients was only higher for the domain of general health perception when compared with the aged-matched general population. Mental health of transplanted patients was even significantly better than in the general population. Equally good scores were found in an Italian follow-up study on transplanted patients aged 18-34 years who were transplanted at a median age of 15 years [93]. Dialysis patients from the LERIC study more often had impaired scores compared with the general population for physical domains, but scores on mental domains were similar or even better. Also, in young adults (median age 19.7, range 16.3-23.4 years) in the UK who survived severe CKD in infancy, significantly lower scores on physical functioning but similar scores on emotional well-being compared with the age-matched general population were found [37]. These high scores on emotional domains are in contrast with scores from patients with adult-onset ESRD treated by dialysis who reported substantially lower scores in the domains related to mental HRQoL [94]. It has been suggested that this difference could be directly related to a nearly life-long chronic disease status: patients with a chronic disease since childhood may have grown up with a lower perception of life than those who acquired a chronic disease in adulthood. Consequently, expectations regarding life of patients in the former group are probably better met, despite physical disabilities.

In terms of social and professional outcomes, several studies have shown that young adult survivors of childhood ESRD struggle to secure gainful employment, complete their education, experience intimate relationships, and live independently [95-102]. A French study assessing 374 adult (aged 24-36) survivors of pediatric transplantation found that professional occupation was similar to the French general population but the unemployment rate was higher: $18.5 \%$ vs. $10.4 \%$; $P<0.01$. This rate is comparable with findings in Dutch adults with ESRD since childhood (19.4\% vs. $11.1 \%$ in the healthy population; $P<0.01$ [92]) and with findings from a German study in 120 middle-aged survivors of pediatric ESRD $(14.0 \%$ vs. $9.0 \%$ in the healthy population; $P<0.01)$ [101]. All studies found relatively lower educational attainment in patients compared with the general population, which partly explains the disadvantage in gaining employment. The LERIC study also found that the low income rate (below national average) was significantly higher in patients than in the general population. Remarkably, the study conducted in the UK among adolescent survivors of severe CKD in infancy found an unemployment rate comparable with the general population (17\% vs. $16.2 \%$ ) [37]. The discrepancy with the French and Dutch data might be partly explained by the younger age at time of investigation in our cohort. As a consequence, the majority of patients were still studying, and only $24 \%$ had a paid job.

\section{Conclusion and recommendations}

ESRD and its treatment have a severe impact on the HRQoL of children, as it affects both physical and emotional 
functioning and interferes with normal daily life. In particular, patients on dialysis are at high risk for impaired HRQoL. Regular assessment of HRQoL, including implementation of patient-reported outcomes, should therefore become part of the standard care in order to identify specific areas for interventions. Potential effective medical and psychosocial strategies are known to improve HRQoL, but more attention must be paid to implementing these strategies. Medically, more effort must be put into implementing treatment regimens that reduce cosmetic side effects and the poor growth rate in children with ESRD. Where the possibility of a successful renal transplant is unlikely, a home HD program that can reduce dietary and fluid restriction and improve freedom and autonomy should be actively explored. Several psychological interventions and initiatives exist that may stimulate such children's ability to cope with ESRD and its treatment by providing capacity and encouraging confidence to manage their own health, participate in social activities, progress in their studies, and remain vigilant in dialysis and posttransplant treatment responsibilities. All studies advocate a multidisciplinary patient-centered approach that promotes shared decision making, control, and self-efficacy in treatment management and educational and vocational opportunities.

Furthermore, several neurocognitive problems, including deficits in IQ, academic achievement, and executive functioning, have been reported in the pediatric ESRD population. Especially for children on dialysis, it is recommended to conduct age-appropriate cognitive and achievement testing on a regular basis. Dialysis units should have on-site educators to complement school-based teaching.

In the long term, adult survivors of pediatric ESRD have impaired physical but encouragingly good mental HRQoL. However, they do experience more difficulties integrating into the working population and building a social and family life.

\section{Research agenda}

Large multicenter and longitudinal studies are warranted to ensure adequate sample size and statistical power to better elucidate changes over time in HRQoL outcomes, to investigate which patient factors (i.e., medical, sociodemographic, and psychosocial) may be related to such change, and to further assess which interventional targets would be most suitable. The implementation of patient-reported outcomes might be a feasible platform to closely monitor HRQoL outcomes over time. Studies should use both generic and diseasespecific questionnaires and obtain information from both patients and parents in order to generate the most comprehensive outcomes. Furthermore, a utility-based approach has recently been used to assess QoL among (pediatric) ESRD patients. This construct assesses the relative desirability of health states and forms the basis of the quality-adjusted life year (QALY) analysis, commonly used by health economists in decisionand cost-effectiveness studies. This approach is a promising addition to the existing health status measurements. However, since these questionnaires have only been used in a few studies among pediatric ESRD patients, further research is required to assess their validity and reliability in this specific population.

Future research should focus not only on evaluating the effect of the proposed interventions longitudinally on HRQoL but also on relevant medical outcomes, such as adherence, biochemical control, and graft survival, thererby acknowledging the difficulties of such studies with so many co-variables.

\section{Key summary points}

1. ESRD in children affects physical and emotional functioning, with an adverse impact on HRQoL and neurocognitive functioning, especially for patients receiving dialysis.

2. Determinants of impaired HRQoL include medical, sociodemographic, and psychosocial factors.

3. Rigorous monitoring of HRQoL and cognitive testing might reveal specific problems at an early stage, facilitating appropriate interventions.

4. Implementation of treatment regimens that reduce cosmetic side effects and poor growth should be pursued.

5. Psychosocial interventions are warranted to stimulate coping strategies to give children the capacity and confidence to manage, and gradually take responsibility for, their own health, as well as progressing in their studies and participating in the wider community.

Financial disclosure statement Nothing to disclose

Conflict of interest None to declare

\section{Questions (Answers are provided following the reference list)}

1. According to the current literature, the overall HRQoL of patients on PD compared with patients on HD is:

(a) Less impaired

(b) Equally impaired

(c) More impaired

(d) No sufficient evidence

2. Which medical factor has not been associated with impaired HRQoL? 

(a) Final height
(b) Side effects of immunosuppressive regimen
(c) Level of serum hemoglobin
(d) Level of serum urea

3. Compared with parent-proxy HRQoL scores, patients report:
(a) Higher HRQoL scores
(b) Lower HRQoL scores
(c) Comparable HRQoL scores
(d) Scores are never obtained from both patients and caregivers

4. Which statement is true regarding sufficient support of adolescent patients?

(a) Adolescent patients should be consciously checked and overheard to prevent them from not following medical recommendations

(b) Adolescent patients should be encouraged to manage their own health and to take responsibility in their treatment

(c) Adolescent patients often do not want to share their experiences and coping strategies with other patients

(d) Adolescent patients should not be informed about risk-taking behaviors, as this could make such behaviors more likely to be attempted

5. The risk for developmental delay regarding neurocognitive functioning is the highest for patients with ESRD onset at age:
(a) $<1$ year
(b) 1-2 years
(c) 2-5 years
(d) $>6$ years

6. Adult survivors of pediatric ESRD report:

(a) High scores on both emotional and physical HRQoL domains

(b) Low scores on both emotional and physical HRQoL domains

(c) High scores on emotional domains but low scores on physical HRQoL domains

(d) Low scores on emotional domains but high scores on physical HRQoL domains

Open Access This article is distributed under the terms of the Creative Commons Attribution 4.0 International License (http:// creativecommons.org/licenses/by/4.0/), which permits unrestricted use, distribution, and reproduction in any medium, provided you give appropriate credit to the original author(s) and the source, provide a link to the Creative Commons license, and indicate if changes were made.

\section{References}

1. McDonald SP, Craig JC (2004) Long-term survival of children with end-stage renal disease. N Engl J Med 350:2654-2662

2. Groothoff JW, Gruppen MP, Offringa M, Hutten J, Lilien MR, Van De Kar NJ, Wolff ED, Davin JC, Heymans HS (2002) Mortality and causes of death of end-stage renal disease in children: a Dutch cohort study. Kidney Int 61:621-629

3. Carr AJ, Gibson B, Robinson PG (2001) Measuring quality of life: Is quality of life determined by expectations or experience? BMJ 322:1240-1243

4. Eiser C, Jenney M (2007) Measuring quality of life. Arch Dis Child 92:348-350

5. Matza LS, Swensen AR, Flood EM, Secnik K, Leidy NK (2004) Assessment of health-related quality of life in children: a review of conceptual, methodological, and regulatory issues. Value Health 7:79-92

6. World Health Organization (1993) Measurement of quality of life in children: report of a WHO/IACAPAP Working Party. London, UK. Available from: http://www.who.int/mental health/media/en/663.pdf

7. FDA (2009) Guidance for industry: patient-reported outcomes measures: use in medical product development to support labeling claims. Food and Drug Administration. U.S. Department of Helath and Human Services, Rockville. Available from: http:/ www.fda.gov/downloads/Drugs/Guidances/UCM193282.pdf

8. Goldstein SL, Graham N, Burwinkle T, Warady B, Farrah R, Varni JW (2006) Health-related quality of life in pediatric patients with ESRD. Pediatr Nephrol 21:846-850

9. Neul SK, Minard CG, Currier H, Goldstein SL (2013) Healthrelated quality of life functioning over a 2-year period in children with end-stage renal disease. Pediatr Nephrol 28:285-293

10. Park KS, Hwang YJ, Cho MH, Ko CW, Ha IS, Kang HG, Cheong HI, Park YS, Lee YJ, Lee JH, Cho HY (2012) Quality of life in children with end-stage renal disease based on a PedsQL ESRD module. Pediatr Nephrol 27:2293-2300

11. Riano-Galan I, Malaga S, Rajmil L, Ariceta G, Navarro M, Loris C, Vallo A (2009) Quality of life of adolescents with end-stage renal disease and kidney transplant. Pediatr Nephrol 24: $1561-1568$

12. Goldstein SL, Graham N, Warady BA, Seikaly M, McDonald R, Burwinkle TM, Limbers CA, Varni JW (2008) Measuring health-related quality of life in children with ESRD: performance of the generic and ESRD-specific instrument of the Pediatric Quality of Life Inventory (PedsQL). Am J Kidney Dis 51:285-297

13. Anthony SJ, Hebert D, Todd L, Korus M, Langlois V, Pool R, Robinson LA, Williams A, Pollock-BarZiv SM (2010) Child and parental perspectives of multidimensional quality of life outcomes after kidney transplantation. Pediatr Transplant 14:249-256

14. Buyan N, Turkmen MA, Bilge I, Baskin E, Haberal M, Bilginer Y, Mir S, Emre S, Akman S, Ozkaya O, Fidan K, Alpay H, Kavukcu S, Sever L, Ozcakar ZB, Dogrucan N (2010) Quality of life in children with chronic kidney disease (with child and parent assessments). Pediatr Nephrol 25:1487-1496

15. Qvist E, Narhi V, Apajasalo M, Ronnholm K, Jalanko H, Almqvist F, Holmberg C (2004) Psychosocial adjustment and quality of life after renal transplantation in early childhood. Pediatr Transplant 8: $120-125$

16. Sundaram SS, Landgraf JM, Neighbors K, Cohn RA, Alonso EM (2007) Adolescent health-related quality of life following liver and kidney transplantation. Am J Transplant 7:982-989

17. Tong A, Wong G, McTaggart S, Henning P, Mackie F, Carroll RP, Howard K, Craig JC (2013) Quality of life of young adults and adolescents with chronic kidney disease. J Pediatr 163:1179-1185 
18. Tong A, Henning P, Wong G, McTaggart S, Mackie F, Carroll RP, Craig JC (2013) Experiences and perspectives of adolescents and young adults with advanced CKD. Am J Kidney Dis 61:375-384

19. Varni JW, Seid M, Kurtin PS (2001) PedsQL 4.0: reliability and validity of the Pediatric Quality of Life Inventory version 4.0 generic core scales in healthy and patient populations. Med Care 39:800-812

20. Starfield B, Bergner M, Ensminger M, Riley A, Ryan S, Green B, McGauhey P, Skinner A, Kim S (1993) Adolescent health status measurement: development of the Child Health and Illness Profile. Pediatrics 91:430-435

21. Landgraf JM, Abetz L, Ware JE (1996) The CHQ User's Manual (ed 1). Health Institute, New England Medical Center, Boston

22. Vogels T, Verrips GH, Verloove-Vanhorick SP, Fekkes M, Kamphuis RP, Koopman HM, Theunissen NC, Wit JM (1998) Measuring health-related quality of life in children: the development of the TACQOL parent form. Qual Life Res 7:457-465

23. Aaronson N, Alonso J, Burnam A, Lohr KN, Patrick DL, Perrin E, Stein RE (2002) Assessing health status and quality-of-life instruments: attributes and review criteria. Qual Life Res 11:193-205

24. Churchill DN, Torrance GW, Taylor DW, Barnes CC, Ludwin D, Shimizu A, Smith EK (1987) Measurement of quality of life in end-stage renal disease: the time trade-off approach. Clin Invest Med 10:14-20

25. Horsman J, Furlong W, Feeny D, Torrance G (2003) The Health Utilities Index (HUI): concepts, measurement properties and applications. Health Qual Life Outcomes 1:54

26. Huang IC, Shenkman EA, Leite W, Knapp CA, Thompson LA, Revicki DA (2009) Agreement was not found in adolescents' quality of life rated by parents and adolescents. J Clin Epidemiol 62: 337-346

27. Vance YH, Morse RC, Jenney ME, Eiser C (2001) Issues in measuring quality of life in childhood cancer: measures, proxies, and parental mental health. J Child Psychol Psychiatry 42:661-667

28. Cremeens J, Eiser C, Blades M (2006) Factors influencing agreement between child self-report and parent proxy-reports on the Pediatric Quality of Life Inventory 4.0 (PedsQL) generic core scales. Health Qual Life Outcomes 4:58

29. Gerson AC, Riley A, Fivush BA, Pham N, Fiorenza J, Robertson J, Chandra M, Trachtman H, Weiss R, Furth SL, Council on Pediatric Nephrology and Urology of New York/New Jersey, Kidney and Urology Foundation of America (2005) Assessing health status and health care utilization in adolescents with chronic kidney disease. J Am Soc Nephrol 16:1427-1432

30. Gerson AC, Wentz A, Abraham AG, Mendley SR, Hooper SR, Butler RW, Gipson DS, Lande MB, Shinnar S, Moxey-Mims MM, Warady BA, Furth SL (2010) Health-related quality of life of children with mild to moderate chronic kidney disease. Pediatrics 125:e349-357

31. Goldstein SL, Rosburg NM, Warady BA, Seikaly M, McDonald R, Limbers C, Varni JW (2009) Pediatric end stage renal disease health-related quality of life differs by modality: a PedsQL ESRD analysis. Pediatr Nephrol 24:1553-1560

32. Heath J, Mackinlay D, Watson AR, Hames A, Wirz L, Scott S, Klewchuk E, Milford D, McHugh K (2011) Self-reported quality of life in children and young people with chronic kidney disease. Pediatr Nephrol 26:767-773

33. Tong A, Morton R, Howard K, McTaggart S, Craig JC (2011) "When I had my transplant, I became normal." Adolescent perspectives on life after kidney transplantation. Pediatr Transplant 15:285-293

34. Tong A, Tjaden L, Howard K, Wong G, Morton R, Craig JC (2011) Quality of life of adolescent kidney transplant recipients. J Pediatr 159:670-675

35. Schoenmaker NJ, Haverman L, Tromp WF, van der Lee JH, Offringa M, Adams B, Bouts AH, Collard L, Cransberg K, van
Dyck M, Godefroid N, van Hoeck K, Koster-Kamphuis L, Lilien MR, Raes A, Taylan C, Grootenhuis MA, Groothoff JW (2014) Children of non-Western origin with end-stage renal disease in the Netherlands, Belgium and a part of Germany have impaired health-related quality of life compared with Western children. Nephrol Dial Transplant 29:448-457

36. Varni JW, Limbers CA, Burwinkle TM (2007) Impaired healthrelated quality of life in children and adolescents with chronic conditions: a comparative analysis of 10 disease clusters and 33 disease categories/severities utilizing the PedsQL 4.0 Generic Core Scales. Health Qual Life Outcomes 5:43

37. Mekahli D, Ledermann S, Gullett A, Rees L (2014) Evaluation of quality of life by young adult survivors of severe chronic kidney disease in infancy. Pediatr Nephrol 29:1387-1393

38. Lopes M, Ferraro A, Doria Filho U, Kuckzinski E, Koch VH (2011) Quality of life of pediatric patients with lower urinary tract dysfunction and their caregivers. Pediatr Nephrol 26:571-577

39. Dobbels F, Decorte A, Roskams A, Van Damme-Lombaerts R (2010) Health-related quality of life, treatment adherence, symptom experience and depression in adolescent renal transplant patients. Pediatr Transplant 14:216-223

40. Qvist E, Marttinen E, Ronnholm K, Antikainen M, Jalanko H, Sipila I, Holmberg C (2002) Growth after renal transplantation in infancy or early childhood. Pediatr Nephrol 17:438-443

41. Dodson JL, Diener-West M, Gerson AC, Kaskel FJ, Furth SL (2007) An assessment of health related quality of life using the child health and illness profile-adolescent edition in adolescents with chronic kidney disease due to underlying urological disorders. J Urol 178:660-665, discussion 665

42. Fadrowski J, Cole SR, Hwang W, Fiorenza J, Weiss RA, Gerson A, Furth SL (2006) Changes in physical and psychosocial functioning among adolescents with chronic kidney disease. Pediatr Nephrol 21:394-399

43. Harwood L, Johnson B (1999) Weighing risks and taking chances: adolescents' experiences of the regimen after renal transplantation. ANNA J 26:17-21, discussion 22-13

44. Manificat S, Dazord A, Cochat P, Morin D, Plainguet F, Debray D (2003) Quality of life of children and adolescents after kidney or liver transplantation: child, parents and caregiver's point of view. Pediatr Transplant 7:228-235

45. Nevins TE (2002) Non-compliance and its management in teenagers. Pediatr Transplant 6:475-479

46. Watson AR, Hayes WN, Vondrak K, Ariceta G, Schmitt CP, Ekim M, Fischbach M, Edefonti A, Shroff R, Holta T, Zurowska A, Klaus G, Bakkaloglu S, Stefanidis CJ, Van de Walle J, European Paediatric Dialysis Working Group (2013) Factors influencing choice of renal replacement therapy in European paediatric nephrology units. Pediatr Nephrol 28:2361-2368

47. Fischbach M, Warady BA (2009) Peritoneal dialysis prescription in children: bedside principles for optimal practice. Pediatr Nephrol 24:1633-1642, quiz 1640, 1642

48. Moist LM, Port FK, Orzol SM, Young EW, Ostbye T, Wolfe RA, Hulbert-Shearon T, Jones CA, Bloembergen WE (2000) Predictors of loss of residual renal function among new dialysis patients. J Am Soc Nephrol 11:556-564

49. Geary DF, Piva E, Tyrrell J, Gajaria MJ, Picone G, Keating LE, Harvey EA (2005) Home nocturnal hemodialysis in children. J Pediatr 147:383-387

50. Goldstein SL, Silverstein DM, Leung JC, Feig DI, Soletsky B, Knight C, Warady BA (2008) Frequent hemodialysis with NxStage system in pediatric patients receiving maintenance hemodialysis. Pediatr Nephrol 23:129-135

51. Warady BA, Fischbach M, Geary D, Goldstein SL (2007) Frequent hemodialysis in children. Adv Chronic Kidney Dis 14: 297-303 
52. Hoppe A, von Puttkamer C, Linke U, Kahler C, Booss M, Braunauer-Kolberg R, Hofmann K, Joachimsky P, Hirte I, Schley S, Utsch B, Thumfart J, Briese S, Gellermann J, Zimmering M, Querfeld U, Muller D (2011) A hospital-based intermittent nocturnal hemodialysis program for children and adolescents. J Pediatr 158:95-99, 99 e91

53. Al-Uzri A, Matheson M, Gipson DS, Mendley SR, Hooper SR, Yadin O, Rozansky DJ, Moxey-Mims M, Furth SL, Warady BA, Gerson AC, Chronic Kidney Disease in Children Study Group (2013) The impact of short stature on health-related quality of life in children with chronic kidney disease. J Pediatr 163:736-741, e731

54. van Huis M, Bonthuis M, Sahpazova E, Mencarelli F, Spasojević B, Reusz G, Caldas-Afonso A, Bjerre A, Baiko S, Vondrak K, Molchanova EA, Kolvek N, Zaikova N, Böhm M, Ariceta G, Jager KJ, Schaefer F, van Stralen KJ, Groothoff JW (2015) Considerable variations in growth hormone policy and prescription in pediatric end-stage renal disease across European countries - a report from the ESPN/ERA-EDTA registry. Nephrol Dial Tranplant. doi:10.1093/ndt/gfv105

55. Rees L, Mak RH (2011) Nutrition and growth in children with chronic kidney disease. Nat Rev Nephrol 7:615-623

56. Benfield MR, Kohaut EC (1997) Growth hormone is safe in children after renal transplantation. J Pediatr 131:S28-31

57. Gerson A, Hwang W, Fiorenza J, Barth K, Kaskel F, Weiss L, Zelikovsky N, Fivush B, Furth S (2004) Anemia and healthrelated quality of life in adolescents with chronic kidney disease. Am J Kidney Dis 44:1017-1023

58. Eijsermans RM, Creemers DG, Helders PJ, Schroder CH (2004) Motor performance, exercise tolerance, and health-related quality of life in children on dialysis. Pediatr Nephrol 19:1262-1266

59. Gillespie RS, Wolf FM (2004) Intravenous iron therapy in pediatric hemodialysis patients: a meta-analysis. Pediatr Nephrol 19: 662-666

60. Schroder $\mathrm{CH}$, European Pediatric Peritoneal Dialysis Working Group (2003) The management of anemia in pediatric peritoneal dialysis patients. Guidelines by an ad hoc European committee. Pediatr Nephrol 18:805-809

61. von Rueden U, Gosch A, Rajmil L, Bisegger C, Ravens-Sieberer U (2006) Socioeconomic determinants of health related quality of life in childhood and adolescence: results from a European study. J Epidemiol Community Health 60:130-135

62. Grootenhuis MA, Last BF (2001) Children with cancer with different survival perspectives: defensiveness, control strategies, and psychological adjustment. Psychooncology 10:305-314

63. Lawrence K, Stilley CS, Olshansky E, Bender A, Webber SA (2008) Further exploration: maturity and adherence in adolescent and young adult heart transplant recipients. Prog Transplant 18: $50-54$

64. Penkower L, Dew MA, Ellis D, Sereika SM, Kitutu JM, Shapiro R (2003) Psychological distress and adherence to the medical regimen among adolescent renal transplant recipients. Am J Transplant 3:1418-1425

65. Tjaden L, Tong A, Henning P, Groothoff J, Craig JC (2012) Children's experiences of dialysis: a systematic review of qualitative studies. Arch Dis Child 97:395-402

66. Ajarmeh S, Er L, Brin G, Djurdjev O, Dionne JM (2012) The effect of a multidisciplinary care clinic on the outcomes in pediatric chronic kidney disease. Pediatr Nephrol 27:1921-1927

67. Lipstein EA, Muething KA, Dodds CM, Britto MT (2013) "I'm the one taking it": adolescent participation in chronic disease treatment decisions. J Adolesc Health 53:253-259

68. Harden PN, Walsh G, Bandler N, Bradley S, Lonsdale D, Taylor J, Marks SD (2012) Bridging the gap: an integrated paediatric to adult clinical service for young adults with kidney failure. BMJ 344, e 3718
69. Franklin VL, Greene A, Waller A, Greene SA, Pagliari C (2008) Patients' engagement with "Sweet Talk" - a text messaging support system for young people with diabetes. J Med Internet Res 10, e20

70. Kauer SD, Reid SC, Crooke AH, Khor A, Hearps SJ, Jorm AF, Sanci L, Patton G (2012) Self-monitoring using mobile phones in the early stages of adolescent depression: randomized controlled trial. J Med Internet Res 14, e67

71. Stinson JN, McGrath PJ, Hodnett ED, Feldman BM, Duffy CM, Huber AM, Tucker LB, Hetherington CR, Tse SM, Spiegel LR, Campillo S, Gill NK, White ME (2010) An internet-based selfmanagement program with telephone support for adolescents with arthritis: a pilot randomized controlled trial. J Rheumatol 37: 1944-1952

72. Haverman L, Engelen V, van Rossum MA, Heymans HS, Grootenhuis MA (2011) Monitoring health-related quality of life in paediatric practice: development of an innovative web-based application. BMC Pediatr 11:3

73. Haverman L, Verhoof EJ, Maurice-Stam H, Heymans HS, Gerlag DM, van Rossum MA, Grootenhuis MA (2012) Health-related quality of life and psychosocial developmental trajectory in young female beneficiaries with JIA. Rheumatology (Oxford) 51:368-374

74. Brouhard BH, Donaldson LA, Lawry KW, McGowan KR, Drotar D, Davis I, Rose S, Cohn RA, Tejani A (2000) Cognitive functioning in children on dialysis and post-transplantation. Pediatr Transplant 4:261-267

75. Gipson DS, Hooper SR, Duquette PJ, Wetherington CE, Stellwagen KK, Jenkins TL, Ferris ME (2006) Memory and executive functions in pediatric chronic kidney disease. Child Neuropsychol 12:391-405

76. Qvist E, Pihko H, Fagerudd P, Valanne L, Lamminranta S, Karikoski J, Sainio K, Ronnholm K, Jalanko H, Holmberg C (2002) Neurodevelopmental outcome in high-risk patients after renal transplantation in early childhood. Pediatr Transplant 6: $53-62$

77. Hooper SR, Gerson AC, Butler RW, Gipson DS, Mendley SR, Lande MB, Shinnar S, Wentz A, Matheson M, Cox C, Furth SL, Warady BA (2011) Neurocognitive functioning of children and adolescents with mild-to-moderate chronic kidney disease. Clin J Am Soc Nephrol 6:1824-1830

78. Johnson RJ, Warady BA (2013) Long-term neurocognitive outcomes of patients with end-stage renal disease during infancy. Pediatr Nephrol 28:1283-1291

79. Madden SJ, Ledermann SE, Guerrero-Blanco M, Bruce M, Trompeter RS (2003) Cognitive and psychosocial outcome of infants dialysed in infancy. Child Care Health Dev 29:55-61

80. McGraw ME, Haka-Ikse K (1985) Neurologic-developmental sequelae of chronic renal failure in infancy. J Pediatr 106:579-583

81. Rotundo A, Nevins TE, Lipton M, Lockman LA, Mauer SM, Michael AF (1982) Progressive encephalopathy in children with chronic renal insufficiency in infancy. Kidney Int 21:486-491

82. Warady BA, Neu AM, Schaefer F (2014) Optimal care of the infant, child, and adolescent on dialysis: 2014 update. Am J Kidney Dis 64:128-142

83. (2011) North American Pediatric Renal Trials and Collaborative Studies (NAPRTCS). Annual Dialysis Report. Rockville, MD: Emmes Corp. Available from: https://web.emmes.com/study/ ped/annlrept/Annual\%20Report\%20-2008.pdf

84. Davis ID (1999) Pediatric renal transplantation: back to school issues. Transplant Proc 31:61S-62S

85. White CT, Trnka P, Matsell DG (2007) Selected primary care issues and comorbidities in children who are on maintenance dialysis: a review for the pediatric nephrologist. Clin J Am Soc Nephrol 2:847-857

86. Eiser C, Varni JW (2013) Health-related quality of life and symptom reporting: similarities and differences between children and their parents. Eur J Pediatr 172:1299-1304 
87. Kilis-Pstrusinska K, Medynska A, Chmielewska IB, Grenda R, Kluska-Jozwiak A, Leszczynska B, Niedomagala J, Olszak-Szot I, Miklaszewska M, Szczepanska M, Tkaczyk M, Urzykowska A, Wasilewska A, Zachwieja K, Zajaczkowska M, Ziolkowska H, Zagozdzon I, Zwolinska D (2013) Perception of health-related quality of life in children with chronic kidney disease by the patients and their caregivers: multicentre national study results. Qual Life Res 22:2889-2897

88. McKenna AM, Keating LE, Vigneux A, Stevens S, Williams A, Geary DF (2006) Quality of life in children with chronic kidney disease-patient and caregiver assessments. Nephrol Dial Transplant 21:1899-1905

89. Upton P, Lawford J, Eiser C (2008) Parent-child agreement across child health-related quality of life instruments: a review of the literature. Qual Life Res 17:895-913

90. Davis MC, Tucker CM, Fennell RS (1996) Family behavior, adaptation, and treatment adherence of pediatric nephrology patients. Pediatr Nephrol 10:160-166

91. Tong A, Lowe A, Sainsbury P, Craig JC (2008) Experiences of parents who have children with chronic kidney disease: a systematic review of qualitative studies. Pediatrics 121:349-360

92. Tjaden LA, Vogelzang J, Jager KJ, van Stralen KJ, Maurice-Stam H, Grootenhuis MA, Groothoff JW (2014) Long-term quality of life and social outcome of childhood end-stage renal disease. J Pediatr 165:336-342

93. Tozzi AE, Mazzotti E, Di Ciommo VM, Dello Strologo L, Cuttini M (2012) Quality of life in a cohort of patients diagnosed with renal failure in childhood and who received renal transplant. Pediatr Transplant 16:840-845

94. Mazairac AH, de Wit GA, Penne EL, van der Weerd NC, de Jong B, Grooteman MP, van den Dorpel MA, Buskens E, Dekker FW, Nube MJ, Ter Wee PM, Boeschoten EW, Bots ML, Blankestijn PJ, CONTRAST investigators (2011) Changes in quality of life over time-Dutch haemodialysis patients and general population compared. Nephrol Dial Transplant 26:1984-1989

95. Groothoff JW, Grootenhuis MA, Offringa M, Stronks K, Hutten GJ, Heymans HS (2005) Social consequences in adult life of endstage renal disease in childhood. J Pediatr 146:512-517
96. Mellerio H, Alberti C, Labeguerie M, Andriss B, Savoye E, Lassalle M, Jacquelinet C, Loirat C (2014) Adult social and professional outcomes of pediatric renal transplant recipients. Transplantation 97:196-205

97. Grootenhuis MA, Stam H, Last BF, Groothoff JW (2006) The impact of delayed development on the quality of life of adults with end-stage renal disease since childhood. Pediatr Nephrol 21:538544

98. Bartosh SM, Leverson G, Robillard D, Sollinger HW (2003) Long-term outcomes in pediatric renal transplant recipients who survive into adulthood. Transplantation 76: $1195-1200$

99. Broyer M, Le Bihan C, Charbit M, Guest G, Tete MJ, Gagnadoux MF, Niaudet P (2004) Long-term social outcome of children after kidney transplantation. Transplantation 77:1033-1037

100. Groothoff JW, Grootenhuis M, Dommerholt A, Gruppen MP, Offringa M, Heymans HS (2002) Impaired cognition and schooling in adults with end stage renal disease since childhood. Arch Dis Child 87:380-385

101. Offner G, Latta K, Hoyer PF, Baum HJ, Ehrich JH, Pichlmayr R, Brodehl J (1999) Kidney transplanted children come of age. Kidney Int 55:1509-1517

102. Rocha S, Fonseca I, Silva N, Martins LS, Dias L, Henriques AC, Faria S, Costa T, Rocha L, Cabrita A, Mota C (2011) Impact of pediatric kidney transplantation on long-term professional and social outcomes. Transplant Proc 43:120-124

\section{Answers to multiple choice questions}

1. $\mathrm{b}$

2. d

3. a

4. b

5. a

6. c 